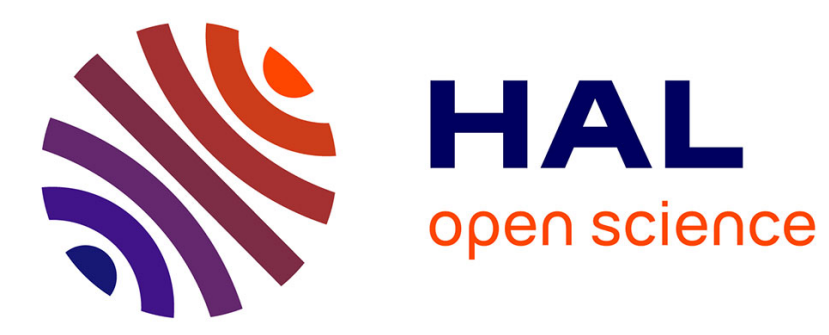

\title{
Understanding Czochralski growth of decagonal AlCoCu
}

Götz Meisterernst, Liming Zhang, Peter Dreier, Peter Gille

\section{To cite this version:}

Götz Meisterernst, Liming Zhang, Peter Dreier, Peter Gille. Understanding Czochralski growth of decagonal AlCoCu. Philosophical Magazine, 2005, 86 (03-05), pp.323-328. 10.1080/14786430500270426 . hal-00513593

\section{HAL Id: hal-00513593 \\ https://hal.science/hal-00513593}

Submitted on 1 Sep 2010

HAL is a multi-disciplinary open access archive for the deposit and dissemination of scientific research documents, whether they are published or not. The documents may come from teaching and research institutions in France or abroad, or from public or private research centers.
L'archive ouverte pluridisciplinaire HAL, est destinée au dépôt et à la diffusion de documents scientifiques de niveau recherche, publiés ou non, émanant des établissements d'enseignement et de recherche français ou étrangers, des laboratoires publics ou privés. 


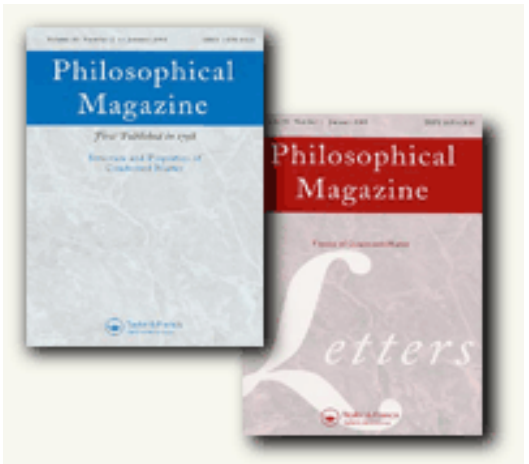

\section{Understanding Czochralski growth of decagonal $\mathrm{AlCoCu}$}

\begin{tabular}{|r|l|}
\hline Journal: & Philosophical Magazine \& Philosophical Magazine Letters \\
\hline Manuscript ID: & TPHM-05-May-0201.R1 \\
\hline Journal Selection: & Philosophical Magazine \\
\hline Date Submitted by the & 05-Jul-2005 \\
\hline Complete List of Authors: & $\begin{array}{l}\text { Meisterernst, Götz; Ludwig-Maximilians-Universität München, } \\
\text { Crystallography Section } \\
\text { Zhang, Liming; Ludwig-Maximilians-Universität München, } \\
\text { Crystallography Section } \\
\text { Dreier, Peter; Ludwig-Maximilians-Universität München, } \\
\text { Crystallography Section } \\
\text { Gille, Peter; Ludwig-Maximilians-Universität München, } \\
\text { Crystallography Section }\end{array}$ \\
\hline Keywords: & quasicrystals, crystal growth \\
\hline Keywords (user supplied): & \begin{tabular}{l} 
AlCoCu, Czochralski growth \\
\hline
\end{tabular} \\
\hline
\end{tabular}

\section{(s) SholaroNE" \\ Manuscript Central}




\title{
Understanding Czochralski growth of decagonal AICoCu
}

\author{
G. Meisterernst, L. Zhang\#, P. Dreier and P. Gille*
}

\begin{abstract}
Crystallography Section, Ludwig-Maximilians-Universität München, Germany
\end{abstract}

\begin{abstract}
Czochralski growth of decagonal AICoCu was investigated using spontaneous nucleation as well as AICoNi seeds of different orientations. Contrary to all knowledge gained with the growth of large single crystals in the Al-Co-Ni system, growth of AICoCu quasicrystals was experienced to be much more complicated. Second-phase inclusions were found to be the main problem resulting in various features that affect regular crystal growth. Even with extremely low pulling rates this could only be solved by growing along the 2-fold [10000]-direction. Finally, large-grain $\mathrm{Al}_{67.5} \mathrm{Co}_{20.0} \mathrm{Cu}_{12.3}$ single crystals, having a rather homogeneous elemental distribution, were successfully grown from the initial melt of composition $\mathrm{Al}_{66} \mathrm{Co}_{10} \mathrm{Cu}_{24}$.
\end{abstract}

Keywords: Quasicrystal; AlCoCu; Czochralski growth

\section{§1. INTRODUCTION}

Although decagonal quasicrystals (D-phase) in the two ternary systems Al-Co-Ni and Al-Co-Cu have been known for quite a long time to be thermodynamically stable phases [1-3], growth of large-grain AICoCu quasicrystals has not been as successful as in the much better understood case of AICoNi. Compared to the Al-Co-Ni phase diagram studies reported by Gödecke et al. [4], little is known about Al-Co-Cu. Grushko [5] has reported on a considerable shift of the decagonal stability field, that moves with decreasing temperature towards a higher Cu content. This shift is even so strong, that the stability regions at temperatures of $1000^{\circ} \mathrm{C}$ and $900^{\circ} \mathrm{C}$ do not overlap at all (see figure 1). Yokoyama et al. [6] as well as Guo et al. [7] have described the $\mathrm{Al}_{65} \mathrm{Co}_{x} \mathrm{Cu}_{35-x}$ isopleth which is assumed to be the most important cut through the ternary phase diagram, because the equilibrium between the decagonal phase and its liquid at approximately $1000^{\circ} \mathrm{C}$ is established at an almost constant $\mathrm{Al}$ content. This is totally different to the Al-Co-Ni system where crystallization occurs from an Al-rich solution. We have published the D-phase primary crystallization field (see figure 1) and crystallization paths in its vicinity obtained from solidification studies using the Bridgman method [8]. From this it is known, that the initial melt composition $\mathrm{Al}_{66} \mathrm{Co}_{10} \mathrm{Cu}_{24}$ used in all experiments of the present study crystallizes at a temperature slightly higher than $1000^{\circ} \mathrm{C}$ with the D-phase being the first-to-freeze solid.

Only little has been reported on successful experiments to grow single crystals of the decagonal phase AICoCu [6 - 10], and consequently, samples being big enough for some investigations which require large grains (e.g. neutron diffraction experiments) are still needed. Yokoyama et al. [6] have reported on decagonal AICoCu growth by the Czochralski method resulting

* current address: Ames Lab, lowa State University, Ames, lowa 50011, USA

*Author for correspondence. Email: gille@Imu.de. 
in a long but low-diameter crystal grown along the periodic axis. Guo et al. [7] succeeded in growing decagonal $\mathrm{Al}_{66} \mathrm{Co}_{17} \mathrm{Cu}_{17}$ as the primary phase using the Bridgman method, but they obtained a few grains instead of a single crystal. More recently, the flux method was applied to AICoCu growth, yielding several prismatic single-grain quasicrystals of a few $\mathrm{mm}$ in diameter [10].

It is the aim of this paper to summarize the results of quite a large number of Czochralski growth experiments which have been carried out to grow large single-grain AlCoCu quasicrystals, and to understand the differences between $\mathrm{AICoCu}$ and successful $\mathrm{AlCoNi}$ quasicrystal growth.

\section{§2. EXPERIMENTS}

At the very beginning, crystal growth of AlCoCu quasicrystals by the Czochralski method was performed in nearly the same way as with AICoNi [11]. Due to the lack of single-crystalline material suitable for the preparation of native seeds at the beginning of this study, we started using spontaneous nucleation on a tapered alumina rod that worked well with AICoNi [12]. Later on the use of [00001]- or [10000]-oriented AICoNi seeds, i.e. growth along the periodic 10-fold axis or along the quaisperiodic 2-fold direction was applied in all experiments to grow AICoCu quasicrystals.

Growth was carried out in the same way and using the same apparatuses as for AICoNi. Details have been described elsewhere [11]. The only essential change is the lower pulling rate of $0.05 \mathrm{~mm} \mathrm{~h}$ ${ }^{1}$ (compared to $0.15 \mathrm{~mm} \mathrm{~h}^{-1}$ with $\mathrm{AlCoNi}$ ) that was applied during the more recent growth runs. An initial melt composition of $\mathrm{Al}_{66} \mathrm{Co}_{10} \mathrm{Cu}_{24}$ was chosen for all experiments allowing a large fraction of $\mathrm{D}$ phase crystallization. To compensate the shift in the melt composition, a slowly but progressively decreasing temperature program of average $60 \mathrm{~K}$ per three weeks was applied.

For the aim of crystal characterization, the crystals were cut into slices of defined orientation, which has been adjusted by X-ray diffraction using the Laue method. Surface preparation was done by both, mechanical and chemical polishing with diamond paste of decreasing grain size and Syton OP-S (Struers) as the final step. Compositional profiles as well as second-phase inclusions were measured by electron-probe microanalysis (EPMA) with a CAMECA SX 50 instrument (15 kV, $10 \mathrm{nA})$ using the $\mathrm{K}_{\alpha}$ lines and pure elemental $\mathrm{Al}, \mathrm{Co}, \mathrm{Cu}$ standards. Phase characterization was carried out by powder X-ray diffraction performed on a STOE diffractometer (Mo-K $\mathrm{K}_{\alpha 1}$ radiation) in the angular range $(2 \theta)$ of 4 to $56^{\circ}$ with a step width of $0.02^{\circ}$.

\section{§3. RESULTS AND DISCUSSION}

Spontaneous nucleation never resulted in single-grain growth of the decagonal AICoCu phase. Instead, several small grains or even a lot of needles with inclusions in between were formed with $\mathrm{Al}_{2} \mathrm{Cu}$ being the dominant second phase. Since the initial melt surely belongs to the D-phase primary crystallization field which is known from differential thermal analysis [8], this can only be explained assuming the supercooling, necessary for spontaneous nucleation, being much too high for nearequilibrium crystal growth. Once the new phase has been formed, it rapidly grows until supercooling collapses. Such a sudden growth is too fast to meet materials transport conditions that have to ensure removal of the remaining Cu-rich melt. Because this was to be observed in quite a series of experiments, it was concluded that nucleation energy for AlCoCu seems to be considerably higher than that for decagonal AICoNi which can easily be nucleated using seeding at a ceramic tip [12]. 
In all growth runs using a decagonal AICoNi seed to initiate crystallization of D-AICoCu we succeeded in transferring the seed orientation to the growing crystal. In an earlier study the complicated situation in the seed/crystal transition region has been described [9]. The existence of a solid solution between the two decagonal phases AICoNi and AICoCu has been assumed at least within a certain range of composition and at typical seeding temperatures. The quaternary solid solution system has not been investigated so far, but there have been arguments given by Grushko et al. [13] for a basic decagonal structure common to all $\mathrm{AlCo}(\mathrm{Cu}, \mathrm{Ni})$ compositions. From this, $\mathrm{Cu}$ can be assumed to compensate for $\mathrm{Ni}$, and $\mathrm{AlCoNi}$ may act as an almost native seed. As with decagonal $\mathrm{AlCoNi}$, crystallization of AICoCu along the periodic axis is known to be magnitudes faster than growth parallel to quasiperiodic directions. This can be learned from the easily formed needles and was the reason why we did most of the experiments with [00001] being the pulling direction. Some of the grown crystals had an outer appearance of an excellent single crystal grown along the 10-fold rotational axis, but Laue diffraction diagrams taken at the cross section showed not exact [00001]orientation but a low-angle spreading of (00001) poles with typical misorientations of a few degrees. Microscopic inspection revealed narrow second-phase inclusions along the direction of growth. This was qualitatively similar to the above mentioned melt inclusion after the sudden break-down of the initial supercooling, but to a much lower extent. In several crystals it only occurred after crystal growth had succeeded quite a long time, thus yielding several $\mathrm{mm}$ of rather perfect $\mathrm{AlCoCu}$ quasicrystals. Again, it could be argued that some kind of constitutional supercooling criterion was not fulfilled and the decision was made to use an even lower pulling rate. That is why, in more recent experiments, use was made of growth rates as low as $0.05 \mathrm{~mm} \mathrm{~h}^{-1}$, which was considered the lowest rate interesting for practical purposes of single crystal preparation.

Nevertheless, inclusions that originate from the remaining melt could not be completely avoided. In the most curious experiment we have obtained the 'crystal' shown in figure 2a. An apparently single-grain crystal was grown along the decagonal direction using a pulling rate of $0.05 \mathrm{~mm} \mathrm{~h}^{-1}$. Although during the experiment well-formed facets could be observed at the periphery of a bulk crystal, after cooling to room temperature only the pictured crystal could be found. It consisted of bundles of decagonal prisms most of them being continuously bent out of shape. Since this result was regarded as only the worsening of the former findings, this 'crystal' was carefully characterized. As can be seen in figure 2a, all crystalline stalks have a 10-fold prismatic shape independent of whether or not they are straight or curved. Within a straight needle no second phase could be found by optical microscopy or EPMA, and X-ray powder diffraction (XPD) of this needle revealed only single-phase decagonal AICoCu. But, different phases could be identified by optical microscopy in a longitudinal section of a bent prism. EPMA measurements resulted in compositions of $\mathrm{Al}_{67} \mathrm{CoCu}_{32}, \mathrm{Al}_{70} \mathrm{Co}_{11} \mathrm{Cu}_{19}$, and $\mathrm{Al}_{60} \mathrm{Co}_{7} \mathrm{Cu}_{33}$, while the decagonal phase consists of $\mathrm{Al}_{66.5} \mathrm{Co}_{16.5} \mathrm{Cu}_{17}$. XPD of the most curved needle to be seen in figure $2 \mathrm{a}$ has revealed $\mathrm{Al}_{2} \mathrm{Cu}$ besides $\mathrm{D}$-AICoCu. From all these results it can be concluded that during growth residual melt had been trapped between decagonal needles. While cooling down, these melt inclusions follow at very narrow distances the same crystallization path that has been described elsewhere [8] for a similar melt composition. Thus, the measured inclusion phases can be identified as $\mathrm{Al}_{2} \mathrm{Cu}, \mathrm{T}-\mathrm{Al}_{7} \mathrm{CoCu}_{2}$, and $\beta-\mathrm{Al}_{3}(\mathrm{Co}, \mathrm{Cu})_{2}$, respectively. The curved appearance of the individual prismatic needles can only be explained by thermal expansion being different in the various 
phases and yielding stress during cooling that bends the needles. To a much lower extent, this might be the origin of the slightly misoriented AICoCu quasicrystals grown along the 10-fold axis. Hindered growth along quasiperiodic directions, such as that perpendicular to the 10-fold axis, which has already found to be the problem with AICoNi prevents the crystal from becoming a really compact material, and each cavity between decagonal columns may trap droplets of melt.

These problems were only recently solved by Czochralski growth with a pulling direction perpendicular to the 10-fold axis. Using this orientation, melt flow induced by the counter-rotation between the crystal and the melt increases material transport at the phase boundary being perpendicular to the slowly growing quasiperiodic direction. Figure $2 \mathrm{~b}$ shows a photograph of a singlegrain AICoCu quasicrystal grown along [10000]. Like the AICoNi crystals pulled in 2-fold directions, the crystal has an elliptic cross section and diameter control has proved to be more complicated compared to the growth along [00001], but no needle-like substructure is seen and cross sections have not revealed any second-phase inclusion. Since crystal growth had been completed by separating the crystal from the melt, the observed prismatic (10000) face could be identified as the former solid/liquid phase boundary and thus the orientation of the seed was preserved.

EPMA measurements yielded the axial as well as the radial elemental distribution on a longitudinal section through such a AICoCu quasicrystal. The axial plot is given in figure 3 , while along the radial direction no inhomogeneity could be resolved. The first-to-freeze composition $\mathrm{Al}_{67.5} \mathrm{Co}_{20.2} \mathrm{Cu}_{12.3}$ from this crystal has been taken to construct the tie-line inserted in figure 1. Although there has been a slightly increasing $\mathrm{Cu}$ content that is compensated by a Co decrease, the crystal can be called rather homogeneous. Several AICoCu crystals grown along the [10000]-direction are currently under more detailed investigation.

\section{§4. CONCLUSIONS}

Decagonal AICoCu growth has been found to be much more difficult compared to AICoNi. The main problems are addressed to some kinetic barrier which hinders radial growth along 2-fold directions and to liquid inclusion formation. Thus, growth parallel to the 10 -fold rotational axis has not resulted in large-grain quasicrystals, while growing along the [10000]-direction using a very low pulling rate yields rather perfect and homogeneous $\mathrm{Al}_{67.5} \mathrm{Co}_{20.2} \mathrm{Cu}_{12.3}$ crystals.

\section{ACKNOWLEDGEMENT}

Financial support by the Deutsche Forschungsgemeinschaft under contract Gi $211 / 3$ is gratefully acknowledged.

\section{REFERENCES}

[1] L.X. He, Y.K. Wu, K.H. Kuo, J. Mater. Sci. 71284 (1988).

[2] A.P. Tsai, A. Inoue, T. Masumoto, Mater. Trans. JIM 30300 (1989).

[3] A.P. Tsai, A. Inoue, T. Masumoto, Mater. Trans. JIM 30463 (1989).

[4] T. Gödecke, M. Scheffer, R. Lück, S. Ritsch, C. Beeli, Z. Metallkd. 89687 (1998).

[5] B. Grushko, J. Non-Cryst. Solids 153\&154 489 (1993).

Deleted: an

Deleted: S

Deleted: The authors would like to thank R. Wunderlich for surface preparation. 
1

2

3

4

5

6

7

8

9

10

11

12

13

14

15

16

17

18

19

20

21

[6] Y. Yokoyama, R. Note, A. Yamaguchi, A. Inoue, K. Fukaura, H. Sunada, Mater. Trans. JIM 40 123 (1999).

[7] J. Guo, E. Abe, T.J. Sato, A.P. Tsai, Jpn. J. Appl. Phys. 38 L1049 (1999).

[8] L.M. Zhang and P. Gille, J. Alloys Comp. 370198 (2004).

[9] P. Gille, P. Dreier, R.-U. Barz, J. Alloys Comp. 3427 (2002).

[10] R.A. Ribeiro, S.L. Bud'ko, F.C. Laabs, M.J. Kramer, P.C. Canfield, Philos. Mag. 841291 (2004).

[11] B. Bauer, G. Meisterernst, J. Härtwig, T. Schenk, P. Gille, Philos. Mag., this volume.

[12] P. Gille, P. Dreier, M. Gräber, T. Scholpp, J. Crystal Growth 20795 (1999).

[13] B. Grushko, D. Holland-Moritz, K. Bickmann, J. Alloys Comp. 236243 (1996). 
CAPTION OF FIGURES

Figure 1: $\quad$ Part of the Al-Co-Cu phase diagram with the D-phase primary crystallization field according to [8] on the right side of the diagram, the temperature-depending $D$ AICoCu stability region given in [5] on the left-hand side, and the tie-line marking the phase relation used in this study.

Figure 2: Decagonal AICoCu quasicrystals grown by the Czochralski method along the 10-fold axis (a) and parallel to the [10000]-direction (b).

Figure 3: $\quad$ Elemental distribution along the central trace of the decagonal AICoCu quasicrystal grown from an $\mathrm{Al}_{66} \mathrm{Co}_{10} \mathrm{Cu}_{24}$ melt. 
Part of the Al-Co-Cu phase diagram with the D-phase primary crystallization field according to [8], the temperature-depending D-AICoCu stability region given in [5], and the tie-line marking the phase relation used in this study. $209 \times 115 \mathrm{~mm}$ (300 x 300 DPI) 

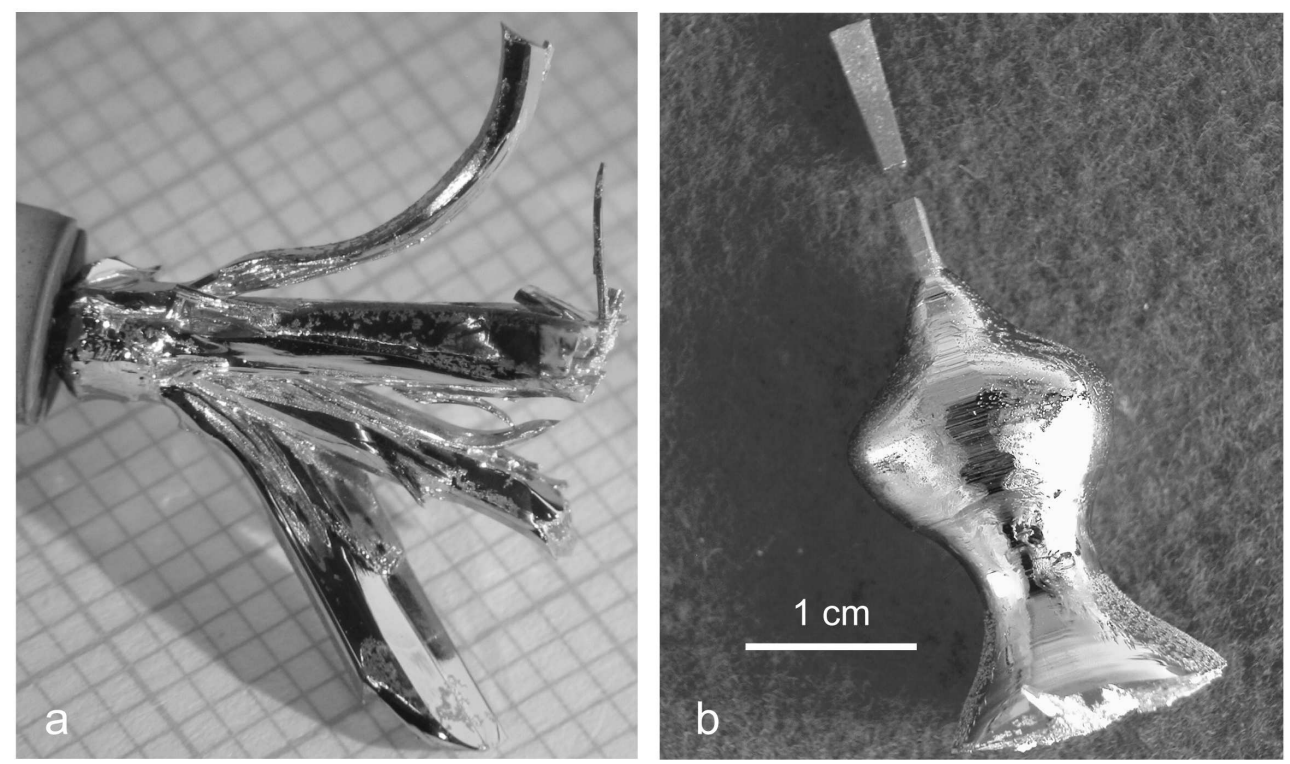

Decagonal AICoCu quasicrystals grown by the Czochralski method along the 10 -fold axis (a) and parallel to the [10000]-direction (b). $201 \times 148 \mathrm{~mm}(300 \times 300$ DPI) 


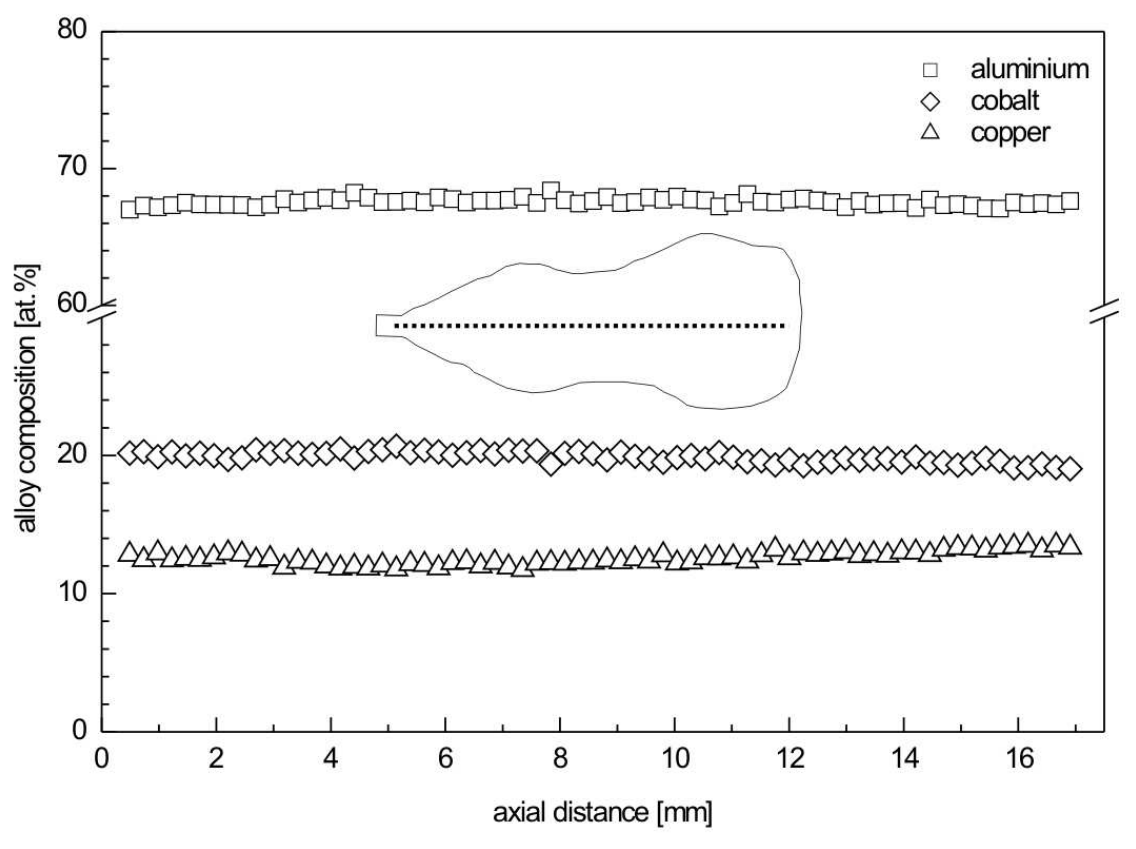

Elemental distribution along the central trace of the decagonal AlCoCu quasicrystal grown from an $\mathrm{Al}_{66} \mathrm{Co}_{10} \mathrm{Cu}_{24}$ melt. 